\title{
Evaluation of radical scavenging activity of rhizome extracts of Alpinia galanga and Zingiber officinale
}

\author{
Manoharan Karuppiah Pillai ${ }^{1}$, Mohd. Zaini Asmawi ${ }^{2}$, Tan Soo Choon ${ }^{1,3}$, \\ Sreenivasan Sasidharan ${ }^{1}$, Subramanion Jothy Lachumy ${ }^{1}$ and Rusli Ismail ${ }^{1,3 *}$
}

${ }^{1}$ Institute for Research in Molecular Medicine (INFORMM), Universiti Sains Malaysia, 11800 Minden, Penang, Malaysia. ${ }^{2}$ School of Pharmaceutical Sciences, Universiti Sains Malaysia, 11800 Minden, Penang, Malaysia.

${ }^{3}$ Institute for Research in Molecular Medicine (INFORMM), Universiti Sains Malaysia, Health Campus, 16150 Kubang Kerian, Kelantan, Malaysia.

Accepted 3 March, 2011

2,2-Diphenyl-1-picrylhydrazyl (DPPH) radical scavenging activity of ethanolic and water extracts of rhizomes of Alpinia galanga (Lengkuas) and two varieties of Zingiber officinale (Ginger) was evaluated. Butylhydroxytoluene (BHT), a known radical scavenger, was used to serve as positive control. Malaysian ginger ethanloic and water extracts from dried ginger (MGEE and MGWED) showed a good to excellent activity. Thailand ginger water extracts from fresh and dried ginger (TGWEF and TGWED) and ethanolic extract from dried ginger (TGEE) exhibited an average to excellent radical scavenging activity. Malaysian lengkuas water extracts from fresh and dried lengkuas (MLWEF and MLWED) and ethanolic extract from dried lengkuas (MLEE) exhibited a good to excellent activity. In addition, the $\mathrm{IC}_{50}$ values were calculated for all the extracts and are listed separately. MGWED, MGEE and MLEE showed IC ${ }_{50}$ values $(<0.03 \mathrm{mg} / \mathrm{mL})$ less than $B H T(\sim 0.12 \mathrm{mg} / \mathrm{mL})$, indicated that these extracts are having better scavenging activity than BHT. TGWEF showed an $\mathrm{IC}_{50}$ value $(\sim 0.13 \mathrm{mg} / \mathrm{mL})$ close to $B H T$. For all other extracts, the $\mathrm{IC}_{50}$ values are slightly higher than $\mathrm{BHT}$.

Key words: Zingiber officinale, Alpinia galanga, Zingiberaceae, radical scavenging activity, antioxidant, butylhydroxytoluene (BHT), ethanolic extract, water extract.

\section{INTRODUCTION}

The by-products of normal metabolism are oxidants such as hydroxyl, alkoxyl, peroxyl free radicals etc. (Multhaug et al., 1997) which are collectively called reactive oxygen species (ROS). The generation of these ROS is a serious concern since they cause oxidative cleavage in lipids, DNA, protein etc. (Maccarrone and Ulrich, 2004) which in turn associated with human degenerative diseases such as cancer, cataracts, cardiovascular diseases, brain disfunction, decline in immune system etc. However, to

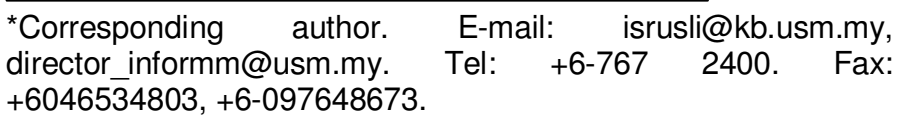

defend from these ailments, the oxidation process is prevented by some radical scavengers called antioxidants (Aruoma, 1994). Antioxidants inhibit these free radicals by any of the processes namely: i) reducing the concentration of ROS; ii) scavenging initiating radicals; iii) breaking chain reaction and iv) chelating the trasition metal catalysts (Maccarrone and Ulrich, 2004). Some examples of antioxidants are glutathione, glutathione peroxidase, tocopherols, transferrin etc. (Maccarrone and Ulrich, 2004).

Although, several synthetic antioxidants such as butylhydroxytoluene (BHT), butylhydroxyanisole (BHA), tbutylhydroxyquinone (TBHQ), propylgallate $(\mathrm{PG})$ etc. have widely been used in industry, their safety become iffy (Juntachote and Berghofer, 2005) and therefore 
several natural antioxidants find their applications in industry (Nakatani, 1997). Fortunately, our dietaries such as fruits, vegetables and beverages derived from plants are a rich source of phenolics and flavonoids which are powerful antioxidants too (Davies, 2000; Halliwell, 2000; Finkel 2000; Halliwell et al., 1998; Kubisch et al., 2006).

Ginger (Zingiber officinale, Zingiberaceae) is one of the most widely used herbals since ancient time and its applications are well documented (Akoachere et al., 2002; Habsah et al., 2002). Especially, the rhizome part of the ginger has been used in traditional medicine (Chan et al., 2008; Vimala et al., 1999), has most potent medicinal properties (Syamkumar et al., 2003) and reported many other biological activities (Habsah et al., 2002; Gugnanai and Ezenwane, 1985; Ficker et al., 2003) including antioxidant property (Mpalantinos et al., 1998; Larson, 1998; Zaepung et al., 2005; El-Ghorab et al., 2010; Shirin and Jamuna, 2010) and plasma antioxidant capacity in experimental animals (Ali et al., 2007). Ginger has been used to aid digestion (Warrier, 1989), to treat stomach upset, diarrhea, nausea, rheumatic complaints (Wagner and Hikino, 1965; Grzanna et al., 2005), high cholesterol, ulcers, depression and impotence (El-Ghorab et al., 2010); to cure hypoglycemic and hypolipidemic complaints (Ahmad and Sharma, 1997); it is more effective in reducing symptoms associated with motion sickness (Afzal et al., 2001) and as such it is better than any other medications. Lengkuas (Alpinia galanga also called greater galangal, Zingiberaceae) is also one of the most widely used herbals, especially in culinary in Asian continent and more specifically in south and southeast Asia. Similar to ginger, the rhizomes of lengkuas also finds its applications in traditional medicine (Yang and Eilerman, 1999) and several bioactive compounds are reported from it (Janssen and Scheffer, 1985; Itokawa et al., 1987; Kondo et al., 1993; Zheng et al., 1993).

Lengkuas has been used as a digestive stimulant, used to get rid of bad breath, bronchial catarrh, rheumatism, throat infections etc. Although, a few varieties of gingers are available in Malaysia, the local Malaysian ginger (vernacular name is Halia Bentong) and Thailand ginger are the two main varieties widely used by all Malaysians in their day to day life. In addition, lengkuas has also been routinely used in culinary in Malaysia. Several reports are available on the antioxidant study of various varieties of lengkuas and ginger including the Malaysian varieties (Ghasemzadeh et al., 2010a, b; Chan et al., 2008).

However, the antioxidant activity of ethanolic and water extracts obtained from fresh and dried Malaysian varieties are not well documented. In our continuing research in molecular medicine, especially the enzyme interaction with herbal extracts and pure natural products, we obtained ethanolic and water extracts from Malaysian and Thailand gingers and Malaysian lengkuas. We envisioned that these extracts can also be extended for their study on 2,2-Diphenyl-1-picrylhydrazyl (DPPH) radical scavenging activity and the results obtained are thus communicated in this study.

\section{MATERIALS AND METHODS}

\section{Plant materials}

$10 \mathrm{~kg}$ each of rhizomes of Malaysian langkuas (collected in June, 2010), Malaysian and Thailand gingers (collected in June 2010 and August 2010, respectively) were purchased from a local market and a voucher specimen, PillaiMK/MY-Lengkuas/06/2010 for Malaysian lengkuas, PillaiMK/MY-Halia/06/2010 for Malaysian ginger and PillaiMK/TH-Halia/08/2010 for Thailand ginger, are separately deposited at the School of Pharmaceutical Sciences, Univeristi Sains Malaysia, Penang, Malaysia and Institute for Research in Molecular Medicine (INFORMM), Universiti Sains Malaysia, Penang, Malaysia.

\section{Processing of materials}

The rhizomes of Malaysian lengkuas, Malaysian and Thailand gingers were all obtained in fresh condition and were cut into small pieces by a chopper. About $3 \mathrm{~kg}$ each of this fresh and cut Malaysian lengkuas and Thailand ginger were kept separately to prepare water extracts. The rest of materials were then dried in an oven at 40 to $50^{\circ} \mathrm{C}$ for two to three weeks. The weight of the materials now reduced to about $5 \mathrm{~kg}$ in the case of Malaysian ginger and about $3.5 \mathrm{~kg}$ in the other two cases and they were powdered using a miller.

\section{Preparation of water extracts from fresh materials}

About $3 \mathrm{~kg}$ of the fresh and cut Malaysian lengkuas and Thailand ginger were taken separately in glass jar and three liters of deionised and purified water was added and digested on a water bath at 70 to $80^{\circ} \mathrm{C}$ for one week. The water extract was obtained by simple filtration of this digested material over a filter paper and kept separately. To the residue, another three liters of water was added and repeated the digestion again for one week. The water extract obtained now was combined with previously obtained water extract. The combined water extract was concentrated by two steps. Buchi rotavapour was used first to remove as much as water possible followed by the use of Freeze dryer/Lyophiliser to remove the remaining water. A dark brown dry residue of water extract was obtained on both cases and stored in a refrigerator.

\section{Preparation of water extracts from dried materials}

About $500 \mathrm{~g}$ of the powdered Malaysian ginger was taken in a glass jar and $3 \mathrm{~L}$ of deionised and purified water was added and digested it on a water bath at 70 to $80^{\circ} \mathrm{C}$ for one week. The rest of the procedure was similar as described in the previous paragraph. The same procedure was repeated to obtain water extract from dried and powdered Thailand ginger and Malaysian lengkuas.

\section{Preparation of ethanolic extracts from dried materials}

The rest of the powdered Malaysian ginger was exhaustively extracted with ethanol using a Soxhlet's apparatus. The extract thus 
Table 1. The percentage radical scavenging activity of ethanolic and water extracts of Malaysian lengkuas, Malaysian and Thailand gingers and positive control (BHT) at various concentrations.

\begin{tabular}{|c|c|c|c|c|c|c|c|}
\hline \multirow{2}{*}{ Extract } & \multicolumn{7}{|c|}{ Concentration $(\mathrm{mg} / \mathrm{mL})$} \\
\hline & 0.03 & 0.06 & 0.125 & 0.25 & 0.50 & 1.00 & 2.00 \\
\hline MGWED & $53.40( \pm 2.17)$ & $58.70( \pm 1.39)$ & $61.07( \pm 0.27)$ & $70.50( \pm 2.07)$ & $77.32( \pm 2.48)$ & $83.77( \pm 0.25)$ & $90.61( \pm 0.23)$ \\
\hline MGEE & $50.15( \pm 0.87)$ & $54.51( \pm 1.12)$ & $57.12( \pm 1.06)$ & $59.55( \pm 4.21)$ & $68.11( \pm 1.32)$ & $70.97( \pm 0.75)$ & $78.72( \pm 0.58)$ \\
\hline TGWEF & $4.29( \pm 3.10)$ & $34.14( \pm 7.90)$ & $47.59( \pm 1.55)$ & $64.59( \pm 2.24)$ & $73.95( \pm 0.23)$ & $75.89( \pm 3.40)$ & $85.52( \pm 0.65)$ \\
\hline TGWED & $32.30( \pm 0.05)$ & $33.55( \pm 0.17)$ & $41.83( \pm 1.13)$ & $45.93( \pm 2.47)$ & $49.05( \pm 0.49)$ & $59.08( \pm 0.33)$ & $61.89( \pm 0.06)$ \\
\hline TGEE & $32.74( \pm 17.66)$ & $37.41( \pm 8.41)$ & $42.03( \pm 2.60)$ & $45.54( \pm 8.40)$ & $65.77( \pm 4.49)$ & $75.96( \pm 3.47)$ & $89.87( \pm 2.12)$ \\
\hline MLWEF & $3.32( \pm 2.67)$ & $10.42( \pm 3.72)$ & $12.50( \pm 0.26)$ & $17.72( \pm 3.57)$ & $57.78( \pm 1.61)$ & $61.90( \pm 2.13)$ & $78.79( \pm 5.15)$ \\
\hline MLWED & $7.75( \pm 0.30)$ & $13.70( \pm 0.12)$ & $16.45( \pm 0.11)$ & $30.43( \pm 0.06)$ & $58.58( \pm 3.70)$ & $88.82( \pm 6.00)$ & $92.21( \pm 0.19)$ \\
\hline MLEE & $51.29( \pm 1.98)$ & $54.37( \pm 1.39)$ & $59.88( \pm 0.85)$ & $62.72( \pm 2.46)$ & $64.84( \pm 0.59)$ & $69.68( \pm 0.61)$ & $78.47( \pm 1.01)$ \\
\hline BHT & $38.04( \pm 3.40)$ & $43.43( \pm 0.66)$ & $52.17( \pm 3.94)$ & $67.00( \pm 2.32)$ & $71.42( \pm 1.09)$ & $86.25( \pm 2.78)$ & $92.98( \pm 0.24)$ \\
\hline
\end{tabular}

obtained was filtered over a filter paper to remove any contaminated solid particles and the solvent ethanol was completely removed using a Buchi rotavapour. The same procedure was repeated to obtain ethanolic extract from Malaysian lengkuas and Thailand ginger. A dark brown precipitate of ethanolic crude extract was obtained in all the three cases and kept in a cupboard at room temperature.

\section{DPPH radical scavenging assay and determination of $\mathrm{IC}_{50}$} values

2,2-Diphenyl-1-picrylhydrazyl (DPPH) radical scavenging activity of ethanolic and water extracts of Malaysian lengkuas, Malaysian and Thailand gingers was conducted according to the methods described in the literature (Sasidharan et al., 2007). Briefly, $2.0 \mathrm{mg}$ of extract $/ \mathrm{mL}$ of water was prepared and further dilutions namely: $1.0,0.5,0.125,0.06$ and $0.03 \mathrm{mg} / \mathrm{mL}$ were obtained from it. $50 \mu \mathrm{L}$ of each one of them was separately mixed with $0.004 \mathrm{w} / \mathrm{v} \%$ of DPPH solution in methanol $(80 \% \mathrm{v} / \mathrm{v})$. The mixture without extract sample was used as blank and just spiked with $50 \mu \mathrm{L}$ of methanol. The commercial antioxidant butylhydroxytoluene (BHT, Sigma Aldrich) of the same concentration and further dilutions were prepared which served as positive control and/or comparison. The mixture was incubated for $30 \mathrm{~min}$ and then its optical density was measured at $517 \mathrm{~nm}$. The $\mathrm{IC}_{50}$ values were calculated from graphs by plotting extract concentrations taken in abscissa versus the percentage inhibition of DPPH radical taken in ordinate. The extract concentration that causes $50 \%$ reduction in DPPH initial concentration is defined as the $\mathrm{IC}_{50}$ value of extract. Each experiment was carried out in triplicate and the averages of the three values were used to calculate $\mathrm{IC}_{50}$ values.

Again, the plot of percentage radical scavenging activity against extract concentrations was used for the comparison of the radical scavenging activity at each concentration and standard deviation was calculated for each concentration from the three values of the experiment. The ability to scavenge DPPH radical was calculated by the following equation:

DPPH radical scavenging activity $(\%)=\left(\left(A_{0}-A_{1}\right) / A_{0}\right) \times 100$

Where: $A_{0}=$ optical density of $\mathrm{DPPH}$ radical + methanol, $\mathrm{A}_{1}=$ optical density of radical + extract or BHT

\section{RESULTS AND DISCUSSION}

DPPH radical scavenging activity of ethanolic and water extracts of Malaysian lengkuas, Malaysian and Thailand gingers was evaluated. The percentage radical scavenging activity of these ethanolic and water extracts at various concentrations are given in Figure $1 \mathrm{~A}$ to $\mathrm{C}$ and Table 1. MGWEF: Malaysian ginger water extract obtained from fresh ginger; MGWED: Malaysian ginger water extract obtained from dried ginger powder; MGEE: Malaysian ginger ethanolic extract obtained from dried ginger powder; TGWEF: Thailand ginger water extract obtained from fresh ginger; TGWED: Thailand ginger water extract obtained from dried ginger powder; TGEE: Thailand ginger ethanolic extract obtained from dried ginger powder; MLWEF: Malaysian lengkuas water extract obtained from fresh lengkuas; MLWED: Malaysian lengkuas water extract obtained from dried lengkuas powder; MLEE: Malaysian lengkuas ethanolic extract obtained from dried lengkuas powder; BHT: Butylhydroxytoluene (positive control). All experiments were conducted in triplicate $(n=3)$ and reported as mean of the three values along with standard deviation, $\pm S D$. In general, Malaysian ginger water extract obtained from dried ginger powder (MGWED) showed slightly higher radical scavenging activity than Malaysian ginger ethanolic extract obtained from dried ginger powder (MGEE) at all concentrations (Figure $1 \mathrm{~A}$ and Table 1). The positive control (BHT) exhibited an activity of about $93 \%$ at a concentration of $2.0 \mathrm{mg} / \mathrm{mL}$ and MGWED showed comparable activity with positive control but MGEE showed lesser activity than positive control at the same concentration. MGWED also showed comparable activity with positive control at a concentration of 1.0 $\mathrm{mg} / \mathrm{mL}$ and slightly higher activity at all other concentrations (Figure 1A and Table 1).

MGWEF: Malaysian ginger water extract obtained from fresh ginger; MGWED: Malaysian ginger water extract 
A

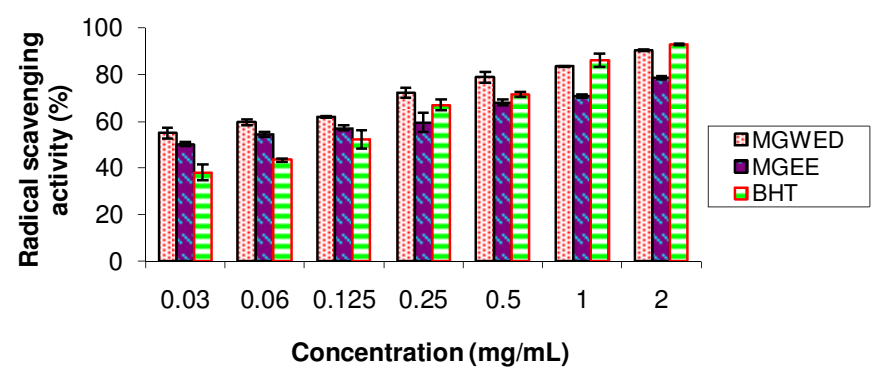

B

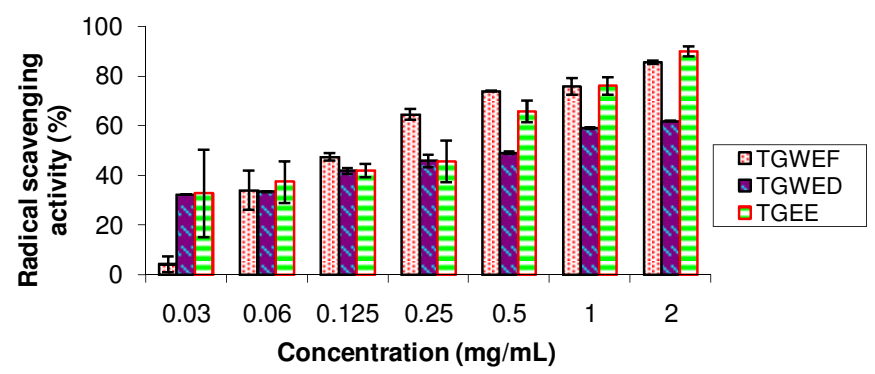

C

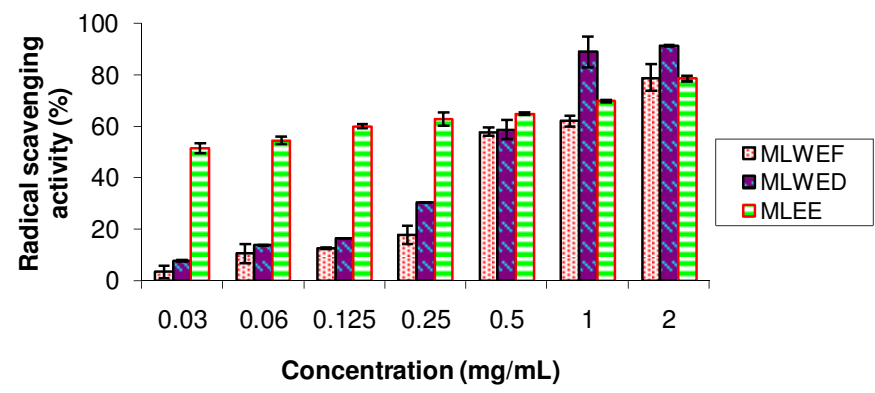

Figure 1. The percentage radical scavenging activity of ethanolic and water extracts of Malaysian lengkuas, Malaysian and Thailand gingers and positive control (BHT) at various concentrations.

Table 2. The $I_{50}$ values of alcoholic and water extracts of Malaysian lengkuas, Malaysian and Thailand gingers and positive control based on DPPH radical scavenging assay.

\begin{tabular}{ccc}
\hline $\mathbf{S} / \mathbf{N}$ & Extract & $\mathbf{I C}_{\mathbf{5 0}}$ value $\mathbf{( m \mathbf { g } / \mathbf { m L } )}$ \\
\hline 1 & MGWED & $<0.03$ \\
2 & MGEE & $<0.03$ \\
3 & TGWEF & $\sim 0.13$ \\
4 & TGWED & $\sim 0.49$ \\
5 & TGEE & $\sim 0.28$ \\
6 & MLWEF & $\sim 0.47$ \\
7 & MLWED & $\sim 0.32$ \\
8 & MLEE & $<0.03$ \\
9 & BHT & $\sim 0.12$ \\
\hline
\end{tabular}

obtained from dried ginger powder; TGEE: Thailand ginger ethanolic extract obtained from dried ginger powder; MLWEF: Malaysian lengkuas water extract obtained from fresh lengkuas; MLWED: Malaysian lengkuas water extract obtained from dried lengkuas powder; MLEE: Malaysian lengkuas ethanolic extract obtained from dried lengkuas powder; BHT: Butylhydroxytoluene (Positive control). All experiments were conducted in triplicate $(n=$ 3 ) and reported as mean of the three values along with standard deviation, $\pm S D$. Both Thailand ginger water extract obtained from fresh ginger (TGWEF) and Thailand ginger water extract obtained from dried ginger powder (TGEE) showed comparable activity at a concentration of $1 \mathrm{mg} / \mathrm{mL}$ (Figure 1B and Table 1) but Thailand ginger water extract obtained from dried ginger powder (TGWED) showed relatively lesser activity at the same concentration. TGWEF and TGEE showed over $85 \%$ activity at a concentration of $2 \mathrm{mg} / \mathrm{mL}$ but TGWED showed relatively lesser activity at the same concentration (Figure $1 \mathrm{~B}$ and Table 1). The same trend was observed at concentrations of 0.25 and $0.125 \mathrm{mg} / \mathrm{mL}$. All the three extracts showed almost comparable activity at a concentration of $0.06 \mathrm{mg} / \mathrm{mL}$.

It was also observed that at a concentration of 0.5 $\mathrm{mg} / \mathrm{mL}$ and above, the scavenging activity of TGWEF and TGEE are comparable to positive control, BHT (Figure 1A, B and Table 1). Malaysian lengkuas water extract obtained from fresh lengkuas (MLWEF) and Malaysian lengkuas ethanolic extract obtained from dried lengkuas powder (MLEE) showed comparable activity at a concentration of $2.0 \mathrm{mg} / \mathrm{mL}$. However, Malaysian lengkuas water extract obtained from dried lengkuas powder (MLWED) exhibited higher activity than MLWEF and MLEE at the same concentration. At a concentration of $1 \mathrm{mg} / \mathrm{mL}$, MLWED exhibited higher activity than both MLWEF and MLEE. At a concentration of $0.5 \mathrm{mg} / \mathrm{mL}$, both MLWED and MLWEF showed a comparable activity but MLEE showed slightly better activity. At all other concentrations, MLEE showed significantly higher activity than MLEWF and MLWED (Figure $1 \mathrm{C}$ and Table 1). The $I_{50}$ values were calculated from the plot of percentage inhibition of DPPH radical by ethanolic and water extracts of Malaysian lengkuas, Malaysian and Thailand gingers and positive control against their different concentrations and listed in Table 2.

MGWED: Malaysian ginger water extract obtained from dried ginger powder; MGEE: Malaysian ginger ethanolic extract obtained from dried ginger powder; TGWEF: Thailand ginger water extract obtained from fresh ginger; TGWED: Thailand ginger water extract obtained from dried ginger powder; TGEE: Thailand ginger ethanolic extract obtained from dried ginger powder; MLWEF: Malaysian lengkuas water extract obtained from fresh lengkuas; MLWED: Malaysian lengkuas water extract obtained from dried lengkuas powder; MLEE: Malaysian lengkuas ethanolic extract obtained from dried lengkuas 
powder; BHT: Butylhydroxytoluene (positive control). Both MGEE and MGWED showed an $\mathrm{IC}_{50}$ value $<0.03$ $\mathrm{mg} / \mathrm{mL}$ and this is lower than the $I_{50}$ value of positive control, BHT, for which it is about $0.12 \mathrm{mg} / \mathrm{mL}$. $\mathrm{IC}_{50}$ value is reciprocally related with activity. This means that both MGEE and MGWED showed better radical scavenging property than positive control. TGWEF, TGWED and TGEE showed $\mathrm{IC}_{50}$ values of about $0.13,0.49$ and 0.28 $\mathrm{mg} / \mathrm{mL}$, respectively (Table 2 ). From these $I_{50}$ values, we observed that TGWEF have almost the same radical scavenging property as that of positive control. However, TGWED and TGEE have slightly lesser radical scavenging property than BHT. Similarly, MLWEF, MLWED and MLEE showed $I_{50}$ values of about 0.47 , 0.32 and $<0.03 \mathrm{mg} / \mathrm{mL}$, respectively (Table 2 ). The low $I_{50}$ value of MLEE revealed that it has better radical scavenging property than positive control. However, both of their water extracts, MLWEF and MLWED, have lesser radical scavenging property than positive control.

Recently, the antioxidant activity at various dilutions of methanolic extracts of leaves stems and rhizomes of two weeks old Malaysian gingers (halia bara and halia bentong) have been reported. Many of them exhibited less than $50 \%$ inhibition and in the cases of rhizome extracts, about 50 to $58 \%$ inhibition was observed (Ghasemzadeh et al., 2010a). The same authors also reported that the aforementioned gingers showed an increased antioxidant property if they were enriched with $\mathrm{CO}_{2}$ (Ghasemzadeh et al., 2010b). However, the antioxidant property of ethanolic and water extracts were not reported. There was another report in which methanolic extract of rhizomes of Malaysian ginger was evaluated for antioxidant property (Chan et al., 2008). In another report, ethanolic extract of rhizomes of Malaysian ginger was used to study in vivo studies on the antioxidant status of hepatocarcinoma induced rats (Ahmad et al., 2006). Similarly, several reports are available on the antioxidant property of different varieties of lengkuas as well as ginger collected from various locations such as Vietnam, Thailand, India etc. (Kruawan and Kangsadalampi, 2006; Stoilova et al., 2007; Juntachote and Berghofer, 2005; Mahae and Chaiseri, 2009; Padma et al., 2006).

\section{Conclusions}

Owing to the safety, natural antioxidants are receiving increasing attention and very much sought after in industry. Both ginger and lengkuas showed promising radical scavenging activity. In addition, they are accepted universally as a safe ingredient in many herbal products and culinary. Therefore, further research will be useful to enable them to fit for industrial needs and they may replace the existing unsafe and undesirable synthetic antioxidants currently used in industry.

\section{ACKNOWLEDGEMENTS}

This research has been supported by a grant from Universiti Sains Malaysia, Malaysia. One of the authors, Manoharan Karuppiah Pillai, thanks the Universiti Sains Malaysia for Post Doctroal Fellowship (PDF). Manoharan Karuppiah Pillai also thanks Mr. Roseli Hassan for his technical assistance at the Traditional Medicine Research Laboratory, School of Pharmaceutical Sciences, Universiti Sains Malaysia.

\section{REFERENCES}

Afzal M, Al-Hadidi D, Menon M, Pesek J, Dhami MS (2001). Ginger: An ethnomedical, chemical and pharmacological review. Drug Metabol. Drug Interact. 18:159-190.

Ahmad N, Sulaiman S, Mukti NA, Murad NA, Hamid NAA, Yus of YAM (2006). Effects of ginger extract (Zingiber officinale Rosce) on antioxidant status of Hepatocarcinoma induced rats. Mal. J. Biochem. Mol. Biol. 14:7-12.

Ahmad R, Sharma S (1997). Biochemical studies on combined effect of garlic (Allium sativum Linn) and ginger (Zingiber officinale Rosc.) in albino rats. Indian J. Exp. Biol. 35:841-843.

Ali TF, Alireza S, Amirabbas F, Ramin S, Yousef R, Ehsan S, Behrooz I, Abdolamir A (2007). The effect of ginger on diabetic nephropathy, plasma antioxidant capacity and lipid peroxidation in rats. Food Chem. 101:148-153.

Akoachere JF, Ndip RN, Chenwi EB, Ndip LM, Njock TE, Anong DN (2002). Antibacterial effect of Zinger officinale and Garcinia kola on respiratory tract pathogens. East Afr. Med. J. 79:588-592.

Aruoma BI (1994). Free radicals and antioxidant strategies in sports. J. Nutr. Biochem. 5:370-381.

Chan EWC, Lim YY, Wong LF, Lianto FS, Wong SK, Lim KK, Joe CE, Lim TY (2008). Antioxidant and tyrosinase inhibition properties of leaves and rhizomes of ginger species. Food Chem. 109:477-483.

Davies KJA (2000). Oxidative stress, antioxidant defencses and damage removal, repair and replacement systems. IUBMB Life 50:279-289.

El-Ghorab AH, Nauman M, Anium FM, Hussain S, Nadeem M (2010). A comparative study and chemical composition and antioxidant activity of ginger (Zingiber officinale) and cumin (Cuminum cyminum). J. Agric. Food Chem. 58:8231-8237.

Ficker C, Smith ML, Akpagana K (2003). Bioassay guided isolation and identification of antifungal compounds from ginger. J. Phytother. Res. 17:897-903.

Finkel T (2000). Oxidants, oxidative stress and the biology of aging. Nature 408:239-248.

Ghasemzadeh A, Jaaffar HZE, Rahmat A (2010a). Antioxidant activities, total phenolics and flavonoids contents in two varieties of Malaysian young ginger (Zingiber officinale Rosce). Molecule 15:4324-4333.

Ghasemzadeh A, Jaaffar HZE, Rahmat A (2010b). Elevated carbon dioxide increases contents flavonoids and phenolic compounds and antioxidant activities in Malaysian young ginger (Zingiber officinale Rosce) varieties. Molecule 15:7907-7922.

Grzanna R, Lindmark L, Frondoza C (2005). Ginger- a herbal medicinal product with broad antiinflammatory actions. J. Med. Food 8:125-32.

Gugnanai HC, Ezenwane EC (1985). Antibacterial activity of extracts of ginger and African oil bean seed. J. Commun. Dis. 17:233-236.

Habsah M, Amran M, Macken MM, Lajis NH, Kikuzaki H, Natkatan NI, Rahman AA, Hafar AM (2002). Screening of zingiberaceae extracts for antimicrobial and antioxidant activities. J. Ethnopharmacol. 72:403-410.

Halliwell B (2000). Oxidative stress markers in human disease: applications to diabetes and to evaluation of the effects antioxidants. In: Packer L, Rosen P, Tritschler HJ, King GL, Azzi A (eds.), Antioxidants 
in Diabetes Management. Marcel Dekker. New York. pp. 33-52.

Halliwell B, Hoult JR, Blake DR (1998). Oxidants, inflammation and antiinflammatory drugs. FASEB J. 2:2867-2873.

Itokawa H, Morita H, Sumitomo T, Totsuka N, Takeya K (1987). Antitumour principles from Alpinia galanga. Planta Med. 53:32-33.

Janssen AM, Scheffer JJC (1985). Acetoxychavicol acetate, an antifungal conponent of Alpinia galanga. Planta Med. 6:507-511.

Juntachote T, Berghofer E (2005). Antioxidant properties and stability of ethanolic extracts of Holy basil and Galangal. Food Chem. 92:193202.

Kondo A, Ohigashi H, Murakami A, Suratwadee J, Koshimizu K (1993). 1'-Acetoxychavicol acetate as potent inhibitor of tumour promoterinduced Epstein-Barr virus activation from Languas galanga, a traditional Thai condiment. Biosci. Biotechnol. Biochem. 57(8):1344-1345.

Kruawan K, Kangsadalampi K (2006). Antioxidant activity, phenolic compound contents and antimutagenic activity of some water extracts of herbs. Thai J. Pharm. Sci. 30:28-35.

Kubisch HM, Wang J, Luche R, Carlson E, Bray TM, Epstein CJ, Philips JP (2006). Transgenic copper/zinc superoxide dismutase modulates susceptibility to type I diabetes. Proc. Nat. Acad. Sci. 91:9956-9959.

Larson RA (1998). The antioxidants of higher plants. Phytochemistry 27:969-978.

Maccarrone M, Ulrich V (2004). Redox regulation in disease and aging. Cell Death Diff. 11:949-951.

Mahae N, Chaiseri S (2009). Antioxidant activities and antioxidative components in extracts of Alpinia galanga (L.) Sw. Kasetsart J. Nat. Sci. 43:358-369.

Mpalantinos MA, De Moura RS, Parente JP, Kuster RM (1998). Biologically active favonoids and kava pyrones from the aqueous extract of Alpinia zerumbet. Phytother. Res. 12:442-444.

Nakatani N (1997). Antioxidants from spices and herbs. In Shahidi F (Ed). Natural antioxidnats: Chemistry, health effects and application. AOAC Press, Champaign. pp. 64-75.

Padma SV, Tiwari V, Singh LW, Swapana N (2006). Antioxidant properties of some exclusive species of Zingiberaceae family of Manipur. EJEAFChe 5(2):1318-1322.
Multhaug G, Ruppert T, Schlicsupp A, Hesse L, Beher D, Colin LM, Beyreuther K (1997). Reactive oxygen species and Alzheimer's disease. Biochem. Pharmacol. 54:533-539.

Sasidharan S, Darah I, Jain NMKM (2007). Free radical scanvenging activity and total phenolic compounds of Gracilaria changii. Int. J. Nat. Eng. Sci. 1:115-117.

Shirin Adel PR, Jamuna P (2010). Chemical composition and antioxidant properties of ginger root (Zingiber officinale). J. Med. Plant. Res. 4:2674-2679.

Stoilova I, Krastanov A, Stoyanova A, Denev P, Gargova S (2007). Antioxidant activity of a ginger extract (Zingiber officinale). Food Chem. 102:764-770.

Syamkumar S, Lowrence B, Sasikumar B (2003). Isolation and amplification of DNA from rhizomes of turmeric and ginger. Plant. Mol. Biol. Rep. 21:171a-171e.

Vimala S, Norhanom AW, Yadav M (1999). Anti-tumour promoter activity in Malaysian ginger rhizobia used in traditional medicine. $\mathrm{Br}$. J. Cancer 80:110-116.

Warrier PK (1989). Spices in Ayurveda. In: George CK, Sivadasan CR, Devakaran D, Sreekumari KP (eds), Strategies for export development of spices. Spices Board, Cochin and International Trade Centre, Geneva. p. 28.

Wagner H, Hikino H (1965). Economic and Medicinal Plants Research (Vol. 1) Eds. Academic Press, New York. p 62.

Yang X, Eilerman RG (1999). Pungent principle of Alpinia galanga (L.) Swartz and its application. J. Agric. Food. Chem. 47:1657-1662.

Zaepung S, Plubrukarn A, Keawpradub N (2005). Cytotoxic and free radical scavenging activities of Zingiberaceous rhizomes. Songklanakarin J. Sci. Technol. 27:799-812.

Zheng GQ, Kenny PM, Lam LKT (1993). Potential anticarcinogenic natural products isolated from lemongrass oil and galanga root oil. $\mathrm{J}$. Agric. Food. Chem. 41:153-156. 